\title{
Determination of the validity and reliability of the Turkish version of the self-rated fall risk questionnaire in older individuals
}

\author{
DOI: https://doi.org/10.5114/pq.2020.95775
}

\author{
Meral Sertel', Tülay Tarsuslu Şimşek ${ }^{2}$, Eylem Tütün Yüminn', Bahar Aras $^{4}$ \\ ${ }^{1}$ Department of Physiotherapy and Rehabilitation, Faculty of Health Sciences, Kırıkkale University, Kırıkkale, Turkey \\ ${ }^{2}$ School of Physical Therapy and Rehabilitation, Dokuz Eylül University, İzmir, Turkey \\ ${ }^{3}$ Department of Physiotherapy and Rehabilitation, Faculty of Health Sciences, Bolu Abant İzzet Baysal University, Bolu, \\ Turkey \\ ${ }^{4}$ Department of Physiotherapy and Rehabilitation, Faculty of Health Science, Kütahya Health Sciences University, \\ Kütahya, Turkey
}

\section{Abstract}

Introduction. The aim was to determine the validity and reliability of the Turkish version of the self-rated fall risk questionnaire (FRQ).

Methods. The study included 100 individuals aged over 65 years. For test-retest reliability, firstly, the questionnaire was applied to volunteers, and, after 15-20 days, the individuals were asked to fill in the questionnaire again. For internal consistency, its correlation was evaluated with the Berg Balance Scale and Timed Up and Go test, of which Turkish reliability and validity studies had been previously performed in older individuals.

Results. The internal consistency of FRQ results obtained in the first (test results) and second (retest results) tests was found to be moderate (Cronbach's alpha coefficient: 0.771 and 0.854 , respectively). The test-retest reliability of the FRQ total score and the total score of the other scales was excellent and turned out to be statistically significant. In the statistical analysis, correlations were observed between both the test results and the retest results $(p<0.05)$.

Conclusions. In this study, the Turkish version of $F R Q$, which provides essential data for evaluating fall risk in older individuals and for consulting a specialist for detailed examination if necessary, was found to be highly valid and reliable.

Key words: falls, fall prevention, older adults, risk assessment

\section{Introduction}

Falls constitute a significant health problem in older adults and cause disability, loss of independence, and premature deaths [1], besides the burden they bring in social and economic terms [2]. In the society, 31-38\% of older individuals fall at least once a year, and this rate increases every 10 years after 65 years of age [3].

In the analyses conducted by the United States Centers for Disease Control and Prevention, it is emphasized that one 1 of every 4 individuals aged 65 years and older falls every year, women fall more often than men, and the fall risk increases with age [4]. Falls are a health condition that should be handled as a priority not only for being an act, but also for the situations it creates. Many studies published on the subject in the last 20 years underline that falls are preventable events in older individuals. The prevention requires identifying the individual who is prone to fall, evaluating individual and environmental factors in detail, and informing the person about the precautions that can be taken early $[5,6]$. Aydın Sayılan et al. [7] reported that pain and falling were substantial components of older adults' lives. In clinical and academic studies, it is recommended that pain assessments be included in older adults for determining the risk of postoperative fall. Early detection of the fall risk in individuals and informing those who are prone to fall are among the most effective programs that can be implemented in older adults with relation to falls $[1,6]$.
The Centers for Disease Control and Prevention have prepared many information leaflets in order to raise awareness about falls in older individuals. Significant emphasis on the problem was put in a leaflet entitled 'Stay independent avoid falling,' which they prepared being inspired by the selfrated fall risk questionnaire (FRQ), developed by Rubenstein et al. [8]. The leaflet mainly aims to provide individuals with the ability to assess themselves in terms of the fall risk, to educate them, and to increase their awareness about applying to specialist health personnel as the next step [9]. Similar studies became widespread later on, and the subject of developing self-control and assessment programs for early detection of fall risk in older individuals has been frequently dealt with [10-12].

$\mathrm{FRQ}$, whose validity was studied by Rubenstein et al. in 2011 [8], is a fall risk assessment scale. It consists of 13 items, and a total score is obtained by answering questions as 'yes' or 'no'. A total score of 4 or above is considered as an important indicator of the individual's fall risk. During the assessment, details related to 'why' questions are important and the reasons for the fall risk are also given. The questionnaire provides crucial data, especially on raising awareness in older individuals and their ability to rate themselves [8].

Information on what risk behaviours affect falls in older individuals or how to measure them is limited in our country [13], and the need is emphasized for tools which assess fall risk in the elderly [14]. The evaluation of fall risk in older individuals will make significant contributions to planning and

Correspondence address: Meral Sertel, Department of Physiotherapy and Rehabilitation, Faculty of Health Sciences, Kırıkkale University, Health Campus, Fabrikalar Mah. İbni Sina Cad. No: 12 (Arpalık Pit Location) Center / Kırıkkale, Turkey, e-mail: fzt_meralaksehir@hotmail.com 
developing fall prevention programs by healthcare professionals. Our study designed in this context aims to determine the validity and reliability of the Turkish version of $F R Q$, which was originally developed in English in order to evaluate the fall risk among older adults during daily activities.

\section{Subjects and methods}

\section{Participants}

The study involved 100 individuals over 65 years of age living in their home environment, who met the study criteria and volunteered to participate. The criteria for inclusion were age of 65 years or more, not having cooperation problems (individuals with a mini-mental test score $>24$ ) [15], not having communication difficulties or problems, and volunteering to participate in the study.

Individuals who had uncontrolled hypertension, acute coronary syndrome, cardiac arrhythmia, cardiovascular disease or malignancy, who underwent chemotherapy or radiotherapy causing malignancy, who presented any neurological or orthopaedic disorder that would disturb balance, and who were alcohol- or drug-addicted were not included in the study.

In scale studies, the sample size is determined by taking into account that there should be at least 3 or $5-10$ people for each scale item [8]. Since the original validation study of $\mathrm{FRQ}$ was conducted with 40 individuals, it was planned to include at least 60 older individuals, which was 5 times of the number of items, in order to investigate the validity and reliability of the FRQ Turkish version, consisting of 13 items. The study was completed with 100 elderly participants.

\section{Procedure}

\section{Translation}

For the adaptation study of the questionnaire, firstly, the authors who developed the questionnaire were contacted and the necessary permissions were obtained. An expert performed the translation of the questionnaire from English to Turkish and from Turkish to English. At this stage, the cultural method of questionnaires adaptation proposed by $\mathrm{Ru}-$ benstein et al. [8] was used. For test-retest reliability, firstly, the questionnaire was applied to volunteers, and, after 15-20 days, the same individuals were asked to fill in the assessment questionnaire again.

\section{Study design}

For internal consistency, the correlation was evaluated with the Berg Balance Scale (BBS) and Timed Up and Go test (TUG), of which Turkish reliability and validity studies had been previously performed in older individuals. The sociodemographic data of the elderly included in the study were evaluated with the prepared assessment form.

$\mathrm{FRQ}$ is a scale that evaluates fall risk in older adults. It consists of 13 items. The answers are given as 'yes' (1 point) or 'no' (0 points), and the individuals who score 4 points or more are classified as being at a high fall risk [8].

In TUG, the participant was requested to stand up from the chair they were sitting on, walk 3 meters safely and at a normal speed, turn, walk back, and sit on the chair again; the time was recorded in seconds. The test was started with the patient's feet flat on the floor and arms in the resting position on the armrests. Three repetitions were performed and the best result was recorded $[16,17]$.
BBS assesses the ability of individuals to sustain balance while performing their functional activities. The test is made more difficult by reducing the supporting ground. The balance test consists of 14 items, each scored between 0 (bad) and 4 (best). The highest result obtained from BBS demonstrates the best balance; a score of 0-20 indicates high risk, 21-40 points at medium risk, and 41-56 implies low risk [18]. The adaptation, validity, and reliability studies of the scale in the Turkish population were carried out by Sahin et al. [19].

\section{Statistical analysis}

Descriptive values of the obtained data were calculated as mean $\pm S D$, number, and \%, depending on the type of the measured feature. The one-way ANOVA model was used for the comparison of the scale scores in terms of categorical socio-demographic and some clinical characteristics, and Pearson's correlation analysis served to investigate correlations between numerical demographic characteristics and the questionnaire scores. Differences between the preand post-test scores were evaluated by the $t$-test.

In the test-retest measurements, internal consistency between the items of $F R Q$ was determined by Cronbach's alpha coefficient. The test-retest reliability of the items was examined by the kappa coefficient, and test-retest reliability between the total scores was established by the intra-class correlation coefficient (ICC). Pearson's correlation analysis was used to examine the validity of FRQ. Statistical significance was set at $5 \%$, and PASW (ver. 18) software was applied in the calculations.

\section{Ethical approval}

The research related to human use, performed at Düzce University, has complied with all the relevant national regulations and institutional policies, has followed the tenets of the Declaration of Helsinki, and has been approved by the Non-Interventional Research Ethics Committee (decision No. 2015/66).

\section{Informed consent}

All individuals included in the study were given detailed information about the purpose and methodology of the study and their informed consent was obtained.

\section{Results}

The mean age of the individuals included in the study was $70.92 \pm 6.11$ years. Their socio-demographic and clinical characteristics are presented in Table 1.

The data obtained in the questionnaires applied in the study are summarized in Table 2.

The fall history for the previous 6 months among the individuals included in the study is presented in Table 3. Overall, $30 \%$ of the participants stated that they had fallen 1-3 times within the preceding 6 months; $41 \%$ experienced fear of falling.

\section{Reliability of the self-rated fall risk questionnaire}

FRQ was applied to 100 individuals, and 13 items were involved. The internal consistency of the results obtained at the first inquiry (test results) was found to be moderate (Cronbach's alpha coefficient: 0.771). At the second inquiry (retest results), the internal consistency of the results was also determined to be moderate (Cronbach's alpha coefficient: 0.854). 
Table 1. Socio-demographic and clinical characteristics of the study participants

\begin{tabular}{|c|c|c|}
\hline \multicolumn{2}{|l|}{ Age (years), $\bar{x} \pm S D$} & $70.92 \pm 6.11$ \\
\hline \multicolumn{2}{|l|}{ Height (cm), $\bar{x} \pm S D$} & $163.24 \pm 9.36$ \\
\hline \multicolumn{2}{|l|}{ Weight (kg), $\bar{x} \pm S D$} & $76.91 \pm 12.75$ \\
\hline \multirow{2}{*}{ Gender, $n(\%)$} & Female & $50(50)$ \\
\hline & Male & $50(50)$ \\
\hline \multirow{2}{*}{ Marital status, $n(\%)$} & Married & $72(72)$ \\
\hline & Single & $28(28)$ \\
\hline \multirow{5}{*}{ Education level, $n(\%)$} & Not literate & $31(31)$ \\
\hline & Primary & $46(46)$ \\
\hline & Middle & $12(12)$ \\
\hline & High & $8(8)$ \\
\hline & University & $3(3)$ \\
\hline \multirow{8}{*}{ Chronic disease, $n(\%)$} & No & $27(27)$ \\
\hline & Hypertension & $28(28)$ \\
\hline & Diabetes & $11(11)$ \\
\hline & Rheumatic disease & $5(5)$ \\
\hline & Cardiac insufficiency & $1(1)$ \\
\hline & Chronic lung disease & $1(1)$ \\
\hline & Coronary artery disease & $4(4)$ \\
\hline & Multimorbidity & $24(24)$ \\
\hline \multirow{2}{*}{ Smoking, $n(\%)$} & Yes & $17(17)$ \\
\hline & No & $83(83)$ \\
\hline \multirow{2}{*}{ Alcohol consumption, $n(\%)$} & Yes & $6(6)$ \\
\hline & No & $94(94)$ \\
\hline \multirow{2}{*}{ Vision problem, $n$ (\%) } & Yes & $71(71)$ \\
\hline & No & $29(29)$ \\
\hline \multirow{2}{*}{ Use of glasses, $n(\%)$} & Yes & $61(61)$ \\
\hline & No & $39(39)$ \\
\hline \multirow{2}{*}{ Urinary incontinence, $n(\%)$} & Yes & $19(19)$ \\
\hline & No & $81(81)$ \\
\hline \multirow{2}{*}{ Use of walking aids, $n$ (\%) } & Yes & $21(21)$ \\
\hline & No & $79(79)$ \\
\hline
\end{tabular}

Table 2. Results for TUG, BBS, and FRQ

\begin{tabular}{|l|c|c|}
\hline Measuring tools & $(\bar{x} \pm S D)$ & Min-max \\
\hline TUG & $14.90 \pm 7.37$ & $7.1-55$ \\
\hline BBS & $45.19 \pm 11.81$ & $12-56$ \\
\hline FRQ & $4.55 \pm 3.68$ & $0-13$ \\
\hline
\end{tabular}

TUG - Timed Up and Go test, BBS - Berg Balance Scale, $F R Q$ - self-rated fall risk questionnaire
Table 3. Fall history of the individuals

\begin{tabular}{|l|l|c|}
\hline \multicolumn{2}{|l|}{ Characteristics } & Patients, $n(\%)$ \\
\hline \multirow{4}{*}{$\begin{array}{l}\text { Number of falls within } \\
\text { the previous 6 months }\end{array}$} & Any & $60(60)$ \\
\cline { 2 - 3 } & $1-3$ & $30(30)$ \\
\cline { 2 - 3 } & $4-5$ & $5(5)$ \\
\cline { 2 - 3 } & $>5$ & $5(5)$ \\
\hline \multirow{5}{*}{ Site of falls } & Home & $15(15)$ \\
\cline { 2 - 3 } & Street & $23(23)$ \\
\cline { 2 - 3 } & Garden & 0 \\
\cline { 2 - 3 } & Other & $2(2)$ \\
\hline \multirow{3}{*}{ Fear of falling } & Yes & $41(41)$ \\
\cline { 2 - 3 } & No & $59(59)$ \\
\hline
\end{tabular}


Table 4. Test-retest reliability of FRQ and ICC values for FRQ, TUG, and BBS totals

\begin{tabular}{|c|c|c|}
\hline FRQ items & $\begin{array}{l}\text { Kappa coefficient } \\
\text { (test-retest reliability) }\end{array}$ & $p$ \\
\hline 1 & 1.00 & $<0.0001$ \\
\hline 2 & 1.00 & $<0.0001$ \\
\hline 3 & 1.00 & $<0.0001$ \\
\hline 4 & 0.975 & $<0.0001$ \\
\hline 5 & 0.978 & $<0.0001$ \\
\hline 6 & 0.980 & $<0.0001$ \\
\hline 7 & 1.00 & $<0.0001$ \\
\hline 8 & 0.975 & $<0.0001$ \\
\hline 9 & 1.00 & $<0.0001$ \\
\hline 10 & 0.976 & $<0.0001$ \\
\hline 11 & 1.00 & $<0.0001$ \\
\hline 12 & 0.959 & $<0.0001$ \\
\hline 13 & 0.954 & $<0.0001$ \\
\hline Total scores & ICC & \\
\hline FRQ total score & 0.999 & $<0.0001$ \\
\hline TUG total score & 0.995 & $<0.0001$ \\
\hline BBS total score & 0.99 & $<0.0001$ \\
\hline
\end{tabular}

$\mathrm{FRQ}$ - self-rated fall risk questionnaire, ICC - intra-class correlation coefficient, TUG - Timed Up and Go test, BBS - Berg Balance Scale

Table 5. Correlations between FRQ totals and TUG and BBS scores

\begin{tabular}{|l|c|c|c|}
\hline \multicolumn{2}{|l|}{ Measuring tools } & FRQ total (test) & FRQ total (retest) \\
\hline \multirow{2}{*}{ TUG } & $r$ & 0.451 & 0.441 \\
\cline { 2 - 4 } & $p$ & 0.0001 & 0.0001 \\
\hline \multirow{2}{*}{ BBS } & $r$ & -0.756 & -0.761 \\
\cline { 2 - 4 } & $p$ & 0.0001 & 0.0001 \\
\hline
\end{tabular}

FRQ - self-rated fall risk questionnaire, TUG - Timed Up and Go test, BBS - Berg Balance Scale

When the test-retest reliability was examined on an item basis, excellent level was observed in all 13 items $(p<0.0001$, Table 4). Furthermore, the test-retest reliability of the fall total score and the total score of the other scales was excellent and also turned out to be statistically significant (ICC: 0.999, $p<$ 0.0001) (Table 4).

In the statistical analysis conducted to determine the validity of the test, statistically significant correlations were observed for both the test results and the retest results (Table 5). The total scores of both the test and retest results of $\mathrm{FRQ}$ were determined to have a moderate positive correlation with the TUG score (test: $r=0.451, p=0.0001$; retest: $r=0.441, p=0.0001$ ) and excellent correlation with the BBS score (test: $r=-0.756, p=0.0001$; retest: $r=-0.761, p=0.0001$ ) (Table 5)

\section{Discussion}

The results of our study, which was planned to adapt FRQ to Turkish and evaluate its validity and reliability, demonstrated that the questionnaire had high validity and reliability values.

Since no adaptation of FRQ to another language had been performed before, the results of our study were referred only to the original version of the questionnaire.

Rubenstein et al. [8] investigated the reliability of $F R Q$ by studying 40 older individuals. They divided the participants into 4 age groups: $65-69$ years, $70-74$ years, $75-79$ years, and 80 years and above. The number of individuals aged 80 years and above was higher $(n=26)$. In our study, 100 subjects aged 65 or more years, defined as older adults, were included, and no age grouping was performed. The mean age of the individuals involved was determined to be 70.92 \pm 6.11 years. In the study conducted by Rubenstein et al. [8], the number of subjects who had not fallen in the previous 6 months was 20 (50\%), while there were 8 people (20\%) who had fallen 1 time, 7 people (17.5\%) who had fallen 2 times, 4 people (10\%) who had fallen 3 times, and 1 person $(2.5 \%)$ who had fallen 6 times. In our study, $60 \%$ of the individuals stated that they had not fallen in the preceding 6 months. However, 30 participants (30\%) had fallen 1-3 times, 5 (5\%) had fallen $4-5$ times, and $5(5 \%)$ had fallen more than 5 times in the previous 6 months. The fall history was found to be similar in the individuals in our study. In the research by Rubenstein et al. [8], the fear of falling was observed to occur 'sometimes' in $42.5 \%$ of the subjects, 'not always' in $45 \%$, and 'very often' in $7.5 \%$. In our study, a 'yes' or 'no' answer was sought to the question 'Is there a fear of falling?', and it was established that $41 \%$ of the individuals had a fear of falling. In our study, in which the fall rate was higher, the fear of falling was also detected at higher rates. Research to investigate the fear of falling in the elderly is needed.

Chronic illness, drug use, loss of muscle strength and balance, use of assistive devices, and urinary incontinence may significantly affect fall risk in older people [18, 20-22]. In the original study in which the questionnaire was developed, these factors were investigated, and it was determined that $49.5 \%$ of the individuals did not use assistive devices, $57.5 \%$ did not have urinary incontinence, and $50 \%$ took drugs with various contents [8]. In our study, many factors thought to have a relationship with falls were examined, and it was determined that $71 \%$ of the participants had vision problems, $61 \%$ wore glasses, $19 \%$ had urinary incontinence, $73 \%$ suffered from a chronic disease and took a drug/drugs with various contents, and $21 \%$ used walking aids. In our study, in which the frequency of falls and the fear of falling were found to be higher, the frequency of problems that might be associated with falls was also observed to be higher.

In the original study, the authors also stated that the questionnaire could be used easily by specialist physicians for risk determination and it was significantly associated with many clinical examinations. This reveals once more the importance of early detection of fall-risk-related situations, of taking necessary precautions, and of informing patients [8]. Such studies, as well as information from other validated questionnaires dedicated to the frequency and kind of help that older people need, can aid planning medical care in this very specific population and finally save the healthcare cost $[23,24]$.

In our study, the questionnaire items and total score values were observed to have high reliability. When the kappa values in the original study were examined on an item basis, the values were determined to vary between 0.30 and 0.80 . 
In our study, the kappa values were found to vary between 0.95 and 1 and to be perfectly compatible. The results of the present study also support those obtained from the questions asked in addition to the questionnaire. The high number of individuals with a fall history in the preceding 6 months and the fear of falling were essential indicators that the participants provided fairly consistent answers. In the original study, the authors observed good consistency among some items, but low consistency in some other items. For example, in item 13, the kappa value was determined to be $0.0139(p=0.321)$ for the parameter in which vision problems were explored. The reason for this was stated to be incompatibility between the patient statement and clinical examination findings. While individuals answered the question related to vision problems in their reports as 'no,' clinical evaluations implied that the risk associated with vision was positive. In the reliability study of the questionnaire, the authors stated that the majority of the assessment items were understood, but that the content related to vision in item 13 was not understood very well, had low correlation with the clinical evaluations, and caused confusion. Therefore, they emphasized the requirement of removing the $13^{\text {th }}$ item from the questionnaire, and they reduced the number of items to 12. In our study, as in the original FRQ test, all of the 13 items were investigated, and high reliability was determined in all of them.

To determine the validity of the questionnaire, correlations were examined with TUG and BBS, which are commonly used and considered as the gold standard in the assessment of balance problems and fall risk in older individuals. A correlation at an excellent level was observed; the results demonstrated that FRQ was a very valid method to determine fall risk in older adults.

There are many older individuals in the society who do not know that they run a fall risk or that they need to undergo a health check on this issue. They are not aware of the situation until they fall or until they apply to a hospital for treatment after a fall-related injury. With the increasing older population, many different needs arise. One of these important needs is to take measures to minimize the risk of falls and fall-related injuries. It is critical to have scales or methods that allow individuals to examine and assess themselves before consulting a specialist physician. They will both reduce continuous hospital admissions and turn out very effective in decreasing hospitalization after falls by augmenting the awareness of patients and their relatives. FRQ is an easy-touse questionnaire developed for this purpose. It provides critical data for evaluating the fall risk in older adults and for consulting a specialist physician for a detailed examination, if necessary. In this study, the adaptation of FRQ to the Turkish language and its validity and reliability were assessed, and the questionnaire was determined to have high validity and reliability.

\section{Acknowledgments}

The authors would like to thank all individuals who contributed to the completion of this work, especially the study participants.

\section{Disclosure statement}

No author has any financial interest or received any financial benefit from this research.

\section{Conflict of interest}

The authors state no conflict of interest.

\section{References}

1. Mehraban AH, Mackenzie LA, Byles JE. A self-report home environment screening tool identified older women at risk of falls. J Clin Epidemiol. 2011;64(2):191-199; doi: 10.1016/j.jclinepi.2010.02.013.

2. Salkeld G, Cameron ID, Cumming RG, Easter S, Seymour J, Kurrle SE, et al. Quality of life related to fear of falling and hip fracture in older women: a time trade off study. BMJ. 2000;320(7231):341-346; doi: 10.1136/ bmj.320.7231.341.

3. Łysoń B, Bienias K, Ścibek J, Wit A. Pelvis motion characteristics in case of induced gait perturbation in male and female adults. Adv Rehab. 2019;3:27-33; doi: 10.5114/areh.2019.87746.

4. Centers for Disease Control and Prevention. Check for safety: a home fall prevention checklist for older adults. 2017. Available from: https://www.cdc.gov/steadi/pdf/ STEADI-Brochure-CheckForSafety-508.pdf?utm_ source=All\&utm_medium=social\&utm_campaign= national\%20safety\%20month\&utm_term=na\&utm_ content=na.

5. Tomita MR, Saharan S, Rajendran S, Nochajski SM, Schweitzer JA. Psychometrics of the Home Safety SelfAssessment Tool (HSSAT) to prevent falls in community-dwelling older adults. Am J Occup Ther. 2014;68(6): 711-718; doi: 10.5014/ajot.2014.010801.

6. Rubenstein LZ. Falls in older people: epidemiology, risk factors and strategies for prevention. Age Ageing. 2006; 35(Suppl. 2):ii37-ii41; doi: 10.1093/ageing/afl084.

7. Aydın Sayılan A, Kulakaç N, Saltan A. Determining the relationship between postoperative pain and the risk of falls in older adults. Surg Vasc Nurs. 2019;4:136-141.

8. Rubenstein LZ, Vivrette R, Harker JO, Stevens JA, Kramer BJ. Validating an evidence-based, self-rated fall risk questionnaire (FRQ) for older adults. J Safety Res. 2011;42(6):493-499; doi: 10.1016/j.jsr.2011.08.006.

9. Skelton D, Todd C. What are the main risk factors for falls amongst older people and what are the most effective interventions to prevent these falls? Copenhagen: WHO Regional Office for Europe; 2004. Available from: http://www.euro.who.int/document/E82552.pdf).

10. SOYF. Self risk assessment tool. A fall risk self-assessment checklist - North East LHIN. Final version. 2017. Available from: http://www.nelhin.on.ca/stayonyourfeet. aspx.

11. American Geriatrics Society. 2010 AGS/BGS clinical practice guideline: prevention of falls in older persons. Available from: https://sbgg.org.br/wp-content/uploads/ 2014/10/2010-AGSBGS-Clinical.pdf.

12. Braun BL. Knowledge and perception of fall-related risk factors and fall-reduction techniques among communitydwelling elderly individuals. Phys Ther. 1998;78(12): 1262-1276; doi: 10.1093/ptj/78.12.1262.

13. Clemson L, Bundy AC, Cumming RG, Kay L, Luckett T. Validating the falls behavioural (FaB) scale for older people: a Rasch analysis. Disabil Rehabil. 2008;30(7): 498-506; doi: 10.1080/09638280701355546.

14. Tanıl V, Çetinkaya Y, Sayer V, Avşar D, İskit Y. Evaluating fall risk [in Turkish]. Health Care Acad J. 2014;1(1):21-26.

15. Cuhadar D, Sertbaş G, Tutkun H. Relationship between level of cognitive functions and activities of daily life at elderly people who live in rest home. Anatol J Psychiatry. 2006;7(4):232-239.

16. Lin M-R, Hwang H-F, Hu M-H, Wu H-DI, Wang Y-W, Huang F-C. Psychometric comparisons of the Timed Up and Go, one-leg stand, functional reach, and Tinetti bal- 
ance measures in community-dwelling older people. J Am Geriatr Soc. 2004;52(8):1343-1348; doi: 10.1111/j.15325415.2004.52366.x.

17. Blankevoort CG, van Heuvelen MJG, Scherder EJA. Reliability of six physical performance tests in older people with dementia. Phys Ther. 2013;93(1):69-78; doi: 10.2522/ptj.20110164.

18. Donoghue D. Physiotherapy Research and Older People (PROP) group, Stokes EK. How much change is true change? The minimum detectable change of the Berg Balance Scale in elderly people. J Rehabil Med. 2009;41(5): 343-346; doi: 10.2340/16501977-0337.

19. Sahin F, Yilmaz F, Ozmaden A, Kotevoglu N, Sahin T, Kuran B. Reliability and validity of the Turkish version of the Berg Balance Scale. J Geriatr Phys Ther. 2008;31(1): 32-37; doi: 10.1519/00139143-200831010-00006.

20. Ganz DA, Bao Y, Shekelle PG, Rubenstein LZ. Will my patient fall? JAMA. 2007;297(1):77-86; doi: 10.1001/ jama.297.1.77.

21. Rubenstein LZ, Josephson KR. The epidemiology of falls and syncope. Clin Geriatr Med. 2002;18(2):141-158; doi: 10.1016/s0749-0690(02)00002-2.

22. Yümin ET, Şimşek TT, Sertel $M$, Öztürk $A$, Yümin $M$. The effect of functional mobility and balance on health-related quality of life (HRQoL) among elderly people living at home and those living in nursing home. Arch Gerontol Geriatr. 2011;52(3):e180-e184; doi: 10.1016/j.archger. 2010.10.027.

23. Seidl H, Bowles D, Bock J-O, Brettschneider C, Greiner W, König $\mathrm{H}-\mathrm{H}$, et al. FIMA - a questionnaire to investigate healthcare resources in old age: development and pilot study [in German]. Gesundheitswes. 2015;77(1):46-52; doi: 10.1055/s-0034-1372618.

24. Mazurek J, Sutkowska E, Szcześniak D, Urbańska KM, Rymaszewska J. FIMA, the questionnaire for healthrelated resource use in the elderly population: validity, reliability, and usage of the Polish version in clinical practice. Clin Interv Aging. 2018;13:787-795; doi: 10.2147/ CIA.S158951. 